\title{
Prevalence of Obesity Among Type 2 Diabetes Patients Attending Diabetic Clinic in Nepalgunj Medical College Teaching Hospital
}

\author{
Parajuli $J^{1}$, Swar $\mathrm{NB}^{2}$, Khadka $\mathrm{D}^{3}$, Thapa $\mathrm{N}^{4}$
}

\begin{abstract}
Background: Obesity and type 2 diabetes constitute major public health issues in modern societies worldwide. These two forms frequently coexist, and statistics show that 60-90\% of all patients with type 2 diabetes are or have been obese. Obesity is generally considered to be a strong risk factor for the development of type 2 diabetes mellitus in future. Objectives: This study aims to assess the prevalence of obesity among type 2 diabetes patients attending diabetic clinic in Nepalgunj Medical College Teaching Hospital. Methods: An analytical cross-sectional study was conducted at NGMCTH, kohalpur, Nepal during the period from October 2013 to March 2014. The present study comprised of a total of 385 type 2 diabetic subjects whose BMI was measured during the visit to the diabetic clinic. Respondents' height, weight, age, sex and duration of diabetes were taken as the study variable. Results: Out of total, $51.4 \%$ were female and $48.6 \%$ were male who attended the clinic. The mean age of the study population was $56.20 \pm 11.95$ ( $95 \% \mathrm{Cl}$; $54.47-57.92$ ) of which $38 \%$ were overweight, $4.2 \%$ were obese and $55.8 \%$ had normal BMI. The proportion of overweight in total population is $37.1 \%$ where female type 2 diabetes proportion (41.4\%) was comparatively higher than male(32.6\%). $4.2 \%$ of the total type 2 diabetes were obese and above $(p=0.014)$. Conclusions: High prevalence of overweight and obesity in type 2 diabetics is associated with other serious complications. Ways to control prevent obesity and overweight should be stressed and made known to people of all ages in the population.
\end{abstract}

Key words: BMI, Obesity, overweight, type 2 diabetes

\section{INTRODUCTION}

Diabetes - A global epidemics and a serious public health problem. 382 million people have diabetes in 2013; by 2035 this will rise to 592 million. The number of people with type 2 diabetes is increasing in every country. $80 \%$ of people with diabetes live in low-and middle-income countries. The greatest number of people with diabetes is between 40 and 59 years of age ${ }^{1}$. In Nepal the number of diabetic patients was 436,000 in 2000 and it was projected be $1,328,000$ in Nepal by $2030^{2}$. Healthy dietary habits and lifestyle modifications- the cornerstones of type 2 diabetes prevention and management ${ }^{3}$. The Diabetic Prevention Program suggested that dietary and physical activity changes to produce a 5-7\% weight loss successfully maintains glycemic control in people diagnosed with type 2 diabetes ${ }^{4}$.
1. Mrs. Janaki Parajuli
2. Mr. Narendra Bdr Swar
3. Dr. Dipendra Khadka
4. Prof Narbada Thapa

Address of correspondence:

Mrs. Janaki Parajuli

Department of Community Medicine

Nepalgunj Medical College Teaching Hospital

Kohalpur, Banke, Nepal

E-mail: meetjanaki@hotmail.com
The risk of diabetes mellitus increases independently with increasing age, obesity, and lack of physical activity, ${ }^{5-10}$ and overall mortality rises with body mass index (BMI) level greater than $25 \mathrm{~kg}$ per $\mathrm{m}^{25}$. Obesity is a complex disorder involving appetite regulation and energy metabolism, as the excess of body fat results from an imbalance of intake and expenditure ${ }^{5}$. Obesity is considered a major risk factor for type 2 diabetes ${ }^{6}$. It has been found that the incidence of diabetes increases by a factor of 2-3 fold in obese individuals when obesity is defined as $120 \%$ of ideal weight ${ }^{11}$.

Obesity is a modifiable risk factor for Type 2 diabetes. It not only interferes with effective treatment of hyperglycemia, but also hypertension, and dyslipidemia, cardiovascular disease, cerbrovascular disease, hyperlipidemia, increased incidence of arthritis of the hands and knees, gallbladder disease, sleep apnea. It is also related to chronic back pain and respiratory dysfunction ${ }^{5,6}$. In addition to the increased risk of morbidity and mortality, obesity leads to various psychological stresses that vary from emotional distress to social stigmatization ${ }^{1,6,8}$.

WHO classification of obesity is shown in Table I, the cut-off points of $25 \mathrm{~kg} / \mathrm{m}^{2}$ and $30 \mathrm{~kg} / \mathrm{m}^{2}$ used to define overweight and obesity respectively ${ }^{13,14}$. This study aims to assess the proportion of obesity among type 2 diabetes patients attending diabetic clinic in Nepalgunj Medical College Teaching Hospital. 
Parajuli et al.: Prevalence of Obesity Among Type 2 Diabetes Patients Attending Diabetic Clinic in Nepalgunj Medical College Teaching Hospital

\begin{tabular}{|c|c|c|}
\hline Classification & BMI (Kg/m2) & Risk of developing health problems \\
\hline Underweight & $<18.5$ & Increased \\
\hline Normal Weight & $18.5-24.9$ & Increast \\
\hline Overweight & $25.0-29.9$ & High \\
\hline Obese class I & $30.0-34.9$ & Very High \\
\hline Obese class II & $35.0-39.9$ & Extremely High \\
\hline Obese class III & $>=40.0$ & \\
\hline
\end{tabular}

Table I: International Classification of BMI

\begin{tabular}{|c|c|c|c|}
\hline Variables & Male $(n=187)$ & Female $(n=198)$ & p-value \\
\hline \multicolumn{4}{|l|}{ Age } \\
\hline Mean $\pm S D$ & $56.20 \pm 11.95$ & $52.62 \pm 10.739$ & \multirow{3}{*}{0.02} \\
\hline $95 \% \mathrm{Cl}$ of mean & 54.47-57.92 & 51.11-54.12 & \\
\hline Median & 57 & 53.5 & \\
\hline \multicolumn{4}{|l|}{ Weight (Kg) } \\
\hline Mean \pm SD & $62.40 \pm 8.547$ & $58.32 \pm 9.055$ & \multirow{3}{*}{$<0.0001$} \\
\hline $95 \% \mathrm{Cl}$ of mean & 61.17-63.63 & 57.05-59.59 & \\
\hline Median & 62 & 60 & \\
\hline \multicolumn{4}{|l|}{ Height (cms.) } \\
\hline Mean \pm SD & $160.20 \pm 7.3$ & $155.2 \pm 6.3$ & \multirow{3}{*}{$<0.0001$} \\
\hline $95 \% \mathrm{Cl}$ of mean & 159.15-161.25 & $154.32-156.10$ & \\
\hline Median & 160 & 155 & \\
\hline \multicolumn{4}{|l|}{ BMI (kg/m2) } \\
\hline Mean \pm SD & $24.31 \pm 2.98$ & $24.22 \pm 3.64$ & \multirow{3}{*}{ NS } \\
\hline $95 \% \mathrm{Cl}$ of mean & $23.88-24.74$ & $23.70-24.73$ & \\
\hline Median & 24.14 & 24.49 & \\
\hline \multicolumn{4}{|c|}{ Duration of diabetes (yrs) } \\
\hline Mean \pm SD & $5.13 \pm 4.73$ & $4.39 \pm 3.83$ & \multirow{3}{*}{ NS } \\
\hline $95 \% \mathrm{Cl}$ of mean & $4.45-5.82$ & $3.85-4.92$ & \\
\hline Median & 4 & 3 & \\
\hline
\end{tabular}

Table II: Basic characteristics of the study populations $(n=385)$

\section{METHODS}

An analytical study with cross-sectional design was adopted and 385 type 2 diabetic patients, diagnosed for at least 3 months, from October 2013 to March 2014 were selected from tertiary level care hospital using the systematic random sampling method. The minimum required sample size was calculated as 358 using formula $n=z 2 p q$. 385 were taken as the sample size of the study. Data were collected by a pre-tested, interviewer administered questionnaire.

World Health Organization's criteria for diabetes classification were used to define patients as Type 2 diabetes mellitus $(9,10)$. Experienced medical interns using standard techniques, measured height and weight. Body mass index (BMI) was calculated according to person's weight in kilograms divided by the square of the person's height in meters ${ }^{14}$. Weight was recorded by the calibrated scale in the diabetic clinic; and height was taken in the same setting. Data were entered into a personal computer using SPSS statistical package, a $p$-value of 0.05 or less was considered to represent statistical significance. Descriptive statistics and statistical tests were used as appropriate.

\section{RESULTS}

A total number of 385 patients with 20 years of age or older attended to the diabetic clinic under management since 6 
Parajuli et al.: Prevalence of Obesity Among Type 2 Diabetes Patients Attending Diabetic Clinic in Nepalgunj Medical College Teaching Hospital

months were recruited in the study. Table II shows that the median duration of diabetes mellitus (DM) was 4 years and the mean duration was $5.13 \pm 4.73(95 \% \mathrm{Cl} 4.45-5.82)$. The mean age of the study population was $56.20 \pm 11.95$ (95\% Cl; $54.47-$ 57.92). Most of the patients $68.8 \%$ (265) were recently diagnosed within 5 years. Out of total $38 \%$ were overweight, $4.2 \%$ were obese and $55.8 \%$ had normal BMI. The basic characteristics of the study population is shown in Table II. It illustrates that mean age of male was greater than the female $(p=0.02)$. The mean height and weight of the males were significantly higher than female $(p<0.001)$. However, there was no significant difference between the mean BMI of male and female.

Table III shows sex-specific and age-specific mean BMI values of the study population. Overall, there was no significant difference between male and female mean BMI. When age increased, mean BMI also increased in female type 2 diabetes patients.

Table IV depicts the BMI status of study population on the basis of sex which was statistically significant $(p=0.014)$.The proportion of overweight in total population is $37.1 \%$ where female type 2 diabetes proportion (41.4\%) was comparatively higher than male(32.6\%). $4.2 \%$ of the total type 2 diabetes were obese and above.

\begin{tabular}{|c|c|c|c|c|}
\hline \multirow{2}{*}{ Age } & \multicolumn{2}{|c|}{ Male } & \multicolumn{2}{c|}{ Female } \\
\cline { 2 - 5 } & No & BMI(M \pm SD) & No & BMI(M \pm SD) \\
\hline $20-29$ & 2 & $31.21 \pm 0.00$ & 1 & $21.21 \pm 0.00$ \\
\hline $30-39$ & 10 & $23.63 \pm 3.27$ & 14 & $23.79 \pm 2.83$ \\
\hline $40-49$ & 51 & $24.61 \pm 2.77$ & 67 & $23.80 \pm 3.5$ \\
\hline $50-59$ & 48 & $24.41 \pm 2.25$ & 61 & $24.75 \pm 3.7$ \\
\hline $60+$ & 76 & $23.96 \pm 3.30$ & 55 & $24.29 \pm 3.9$ \\
\hline Total & 187 & $24.31 \pm 2.98$ & 198 & $4.22 \pm 2.99$ \\
\hline
\end{tabular}

Table III: Mean BMI values on the basis of age and sex categorization $(n=385)$

\begin{tabular}{|c|c|c|c|c|}
\hline BMI categorization & $\begin{array}{c}\text { Male } \\
\mathbf{n}(\%)\end{array}$ & $\begin{array}{c}\text { Female } \\
\mathbf{n}(\%)\end{array}$ & $\begin{array}{c}\text { Total } \\
\mathbf{n}(\%)\end{array}$ & p-value \\
\hline Underweight & $1(0.5)$ & $9(4.5)$ & $10(2.6)$ & \\
\cline { 1 - 4 } Normal & $117(62.6)$ & $99(50)$ & $216(56.1)$ & \multirow{2}{*}{0.014} \\
\hline Overweight & $61(32.6)$ & $82(41.4)$ & $143(37.1)$ & \\
\hline Obese and above & $8(4.3)$ & $8(4)$ & $16(4.2)$ & \\
\hline Total & $187(100)$ & $198(100)$ & $385(100)$ & \\
\hline
\end{tabular}

Table IV: BMI status among male and female type 2 diabetes patients $(n=385)$

\section{DISCUSSION}

Obesity is a condition in which excess body fat may put a person's health at risk. In adults, the risk increases independently with increasing BMI and excess abdominal fat. Cardiovascular and other obesity related disease risks increase significantly when BMI exceeds $25 \mathrm{~kg} / \mathrm{m}^{2}$. The risk increases with the extent of obesity and those with a BMI $>40 \mathrm{~kg} / \mathrm{m} 2$ are at highest risk ${ }^{6}$.

Our study shows, out of total 385 type 2 patients who were followed in diabetic clinic, $2.6 \%$ were underweight and $56.1 \%$ BMI within the normal range while $37.1 \%$ were overweight, the percentage of female patients being higher (41.4\%) than male patients $(32.6 \%)$ which was statistically significant $(p=0.014)$. Obesity was found in $4.2 \%$ of the patients. . In consistent with this, a recent study done in tertiary care hospital in Nepal showed that $39.0 \%$ and $11.0 \%$ of the diabetics to be overweight and obese respectively ${ }^{15}$. A study by Ahmed et al. (2007) showed that $67 \%$ of the patients with diabetes mellitus had $\mathrm{BMI} \geq 25 \mathrm{~kg} / \mathrm{m} 2$. Similarly, one study done in Pakistan showed that $61 \%$ of the diabetics had $\mathrm{BMI} \geq 25 \mathrm{~kg} / \mathrm{m}^{16}$. However, higher prevalence was reported in one of the study done in Nigeria, the majority ( $83 \%$ ) of the type 2 diabetic patients were either overweight or obese $\mathrm{e}^{17}$. These findings further support the fact that obesity or excess body fat accumulation is a strong risk factor for type 2 diabetes. The differences in percentage of overweight and obesity among type 2 diabetes in various studies might be due to different factors like geographical variations, life style, occupational status, genetic factor or ethnic differences of the population.

In accordance with the findings observed in other studies, Sharma and Jain 2009, this study also found higher prevalence of abdominal obesity as indexed in female subjects than their male counterparts ${ }^{18}$. Nearly all the female diabetics (94.3\%) had abdominal obesity while only $51.1 \%$ of the male diabetics had abdominal obesity. Besides abdominal obesity, the present study also found that generalized obesity is more prevalent in female diabetics than male diabetics. This fact is also in agreement with several other studies conducted in Nepal ${ }^{19}$ and Nigeria $^{17}$. Hence, in this study, obesity was more prevalent among females than males. The factors that affect these differences may include childbearing, hormonal status and the high female illiteracy rates, which lead to lower female awareness to the importance of their physique $e^{20,21}$. This may further be due to cultural practices that tend to limit physical exertion by females with resultant sedentary habits, obesity and its attendant complications ${ }^{20}$.

\section{CONCLUSIONS}

Based on the findings of the present study, it can be concluded that overweight/obesity persists in diabetic patients. Furthermore, both obesity and central obesity were more prevalent among females than males. Both the diseases are 
closely interlinked, obesity being central to the development of insulin resistance and hence is a strong risk factor for type 2 diabetes. Therefore an important implication from this study is that effective treatment of obesity with sustained weight loss and obesity prevention including lifestyle modifications are important interventions in an effort to reduce the risk for diabetes and other related complications. Public education about obesity and its consequences is strongly recommended. Ways to control, prevent obesity and overweight should be stressed and made known to people of all ages in the population. Education about diabetes mellitus and its complications could be presented in basic simple public lectures that stress the importance of the awareness of this health condition.

\section{REFERENCES}

1. Wild S, Roglic G, Green A, Sicree R, King H. Global prevalence of diabetes: estimates for the year 2000 and projections for 2030. Diabetes Care 2004; 27: 1047-53.

2. Diabetic Facts, IDF, Diabetes Atlas, $4^{\text {th }}$ Edition, 2010. [ $\tan 2011$ $\left.\begin{array}{lll}\mathrm{M} \text { a } & 17\end{array}\right] . \quad A \vee a \mathrm{ilable} \quad \mathrm{from}$ : http://www.worlddiabetesfoundation.org/composite-35.html.

3. Hoskote SS, Joshi SR. Are Indians to be Diabetic? J Assoc Physicians India 2008; 56: 225-226.

4. King H, Aubert RE, Herman WH. Global burden of diabetes 19952025. Prevalence numerical estimation and projection. Diabetes Care 1998; 21:1414-31.

5. Lyznicki JM, Young DC, Riggs JA, Davis RM. Obesity: Assessment and Management in Primary Care. American Family Physician. 2001;63(11):2165-2169.

6. Seidell JC. Effect of Obesity. Medicine International. 1998;20(10):4-8.

7. Kumar S, Barnett AH. Causes of non-insulin dependent diabetes mellitus. Medicine International. 1997 Jul-Aug;:6-9.

8. Khan NM, Hershey CO. Update on Screening for Type 2 Diabetes: the why, who, how, and what of testing and diagnosing. Postgraduate Medicine. 2001;109 (2):27-34.

9. American Diabetic Association: Screening for Diabetes (Position Statement). Diabetes Care.2001;24(1):S21-S24.

10. American Diabetic Association: Screening for Type II Diabetes (Position Statement) Diabetes Care.2000;23:S21-S24.

11. Rudy DR. Endocrinology. In: Rakel RE, editor. Textbook of Family Practice. 4th ed. USA: WB Saunders Company; 1990. pp. 1082-7.

12. Crimmins CJ. Approach to the patient with obesity. In: Goroll AH, editor. Primary care medicine. 2nd ed. JB Lippinicott Company; 1987. pp. 941-951.

13. Zimmet P. Diabetes - Definitions and Classification. Medicine International. 1997 Jul-Aug;1-3.

14. Obesity: Preventing and Managing the Global Epidemic. Report of a WHO Consultation of Obesity. Geneva: 1997. Jun 3-5, World Health Organization.

15. Pandeya A, Sharma M, Regmi P, Basukala A and Lamsal M. Pattern of dyslipidemia and evaluation of non-HDL cholesterol as a marker of risk factor for cardiovascular disease in type 2 diabetes mellitus. Nepal Med. Coll. J.,2012 14(4): 278-282

16. Shera AS, Jawad F, Maqsood A. Prevalence of chronic complications and associated factors in type 2 diabetes. J. Pak. Med. Assoc.,2004 54:54-9.
17. Joseph EU, Fadupin GT, Keshinro O (2004). Prevalence of obesity among type 2 diabetics in Nigeria a case study of patients in Ibadan, Oyo State, Nigeria. Afr. J. Med. Med. Sci., 33(4): 381-4

18. Sharma S, Jain S (2009). Prevalence of Obesity among Type-2 Diabetics. J Hum Ecol. 25: 31-5

19. Shah A, Bhandary S, Malik S L, Risal P, Koju R (2006). A comparative study of body mass index (BMI) in diabetic and nondiabetic individuals in Nepalese population. Kathmandu University Med. J., 4: 4-10.

20. Williamson DF (1993). Descriptive epidemiology of body weight and weight change in U.S. adults. Ann. Int. Med., 119: 646-9.

21. Riyami A (2003). Prevalence and correlates of obesity and central obesity among Omani adults. Saudi Med. J., 24:641-6. 